\title{
THE POLITICS BEHIND DESIGN PROJECTS: WHEN SPACE, ORGANIZATION, AND TECHNOLOGY COLLIDE ${ }^{1}$
}

\author{
Grégory JEMINE, Université de Liège (HEC-Liège/LENTIC) \\ François PICHAULT, Université de Liège (HEC-Liège/LENTIC) \\ Christophe DUBOIS, Université de Liège (Faculty of Social Sciences/CRIS)
}

Purpose: While more and more organizations commit to transformation projects with the aim of redesigning simultaneously their workspaces, work organization, and technologies, the design process supporting such projects remains largely understudied. This paper examines the political tensions that occur when such processes unfold as well as their implications for project management. By doing so, the paper counterbalances the prescriptive and normative literature on "New Ways of Working" which largely overlooks the political complexity of such projects.

Methods: The paper is based on a qualitative study of a triple design process in a media company. Data collection mainly consists of a nine-month process of non-participant observation of weekly meetings held by the strategic group in charge of the project. Semi-structured interviews with members of the executive committee have also been conducted.

Findings: The analysis illustrates how space, organization, and technology are gradually designed and structured. Four interconnected and often concealed mechanisms that support triple design processes are identified: political tensions, unexpected twists, conflicting temporalities, and arbitration measures.

Originality: The originality of the paper lies in breaking down the concept of design in three separate objects - organization, space, and technology - and examining how these objects were conjointly problematized by an organization in transformation, whereas existing studies often investigate organization design, space design, or technology design in isolation.

Keywords: design process, New Ways of Working, NWoW, NWW, triple design, project management, organizational change, organizational politics

\footnotetext{
${ }^{1}$ This is a preprint version of a paper accepted for publication in the International Journal of Managing Projects in Business. Please use the following reference: Jemine, G., Pichault, F. E Dubois, C. (2020). The politics behind design projects: when space, organization and technology collide. International Journal of Managing Projects in Business, DOI: 10.1108/IJMPB-01-2020-0020

(C) International Journal of Managing Projects in Business. This manuscript is provided for your own personal use only. It may not be used for resale, reprinting, systematic distribution, emailing, or for any other commercial purpose without the permission of the publisher.
} 


\section{Introduction}

In a recent paper, Våland and Georg (2014) coined the term "double design" to designate the processes aiming at reshaping simultaneously architectural spaces and organizational structures. As the authors explain, double design originates from organizational leaders' conviction that "architectural and organizational design processes may be mutually supportive" and should be conducted simultaneously (Våland and Georg, 2014, p.392). The literature in organization and management studies indeed suggests that many firms and businesses have been simultaneously committed to projects involving new workspaces and so-called "innovative" ways of organizing work (De Leede, 2017; Jemine et al., 2019; Kingma, 2018). Relocating one or several buildings, for instance, is increasingly viewed by strategic deciders as an "opportunity" to promote and legitimize alternative organizational forms while saving space and costs (Jemine et al., 2019; Våland and Georg, 2014). The rise of change projects involving "double design" may be partly explained by the development of popular management ideas assuming that some characteristics of space favor the adoption of new ways of organizing work. Many consulting companies now seem convinced that generating major organizational changes ideally requires new spatial settings (Markus and Cameron, 2002; Veldhoen, 2005). Therefore, while modern management fashions such as "New Ways of Working" (Kingma, 2018) and "agile working" (Jeyasingham, 2016) primarily seek to transform organizational cultures and structures, they are also explicitly entrusting space to produce significant organizational effects, such as increased flexibility, transparency, and mobility, trust-based relationships, and improved productivity at work (Fauconneau-Dufresne et al., 2018; Jeyasingham, 2016).

Moreover, promoters of "New Ways of Working" usually prompt organizations to commit not only to architectural and organizational changes but also to technological overhauls. This is best illustrated by the increasingly popular triptych "Bricks, Bytes, Behaviors" that underlies numerous projects of organizational transformation (Jemine et al., 2019; Kingma, 2018) and is even presented as the "go-to" method to implement new ways of working (Baane, 2011; Kok et al., 2015). Contemporary technology is supposed to support the desired transformations by "empowering" people and allowing them to work "anytime, anywhere, anyhow" (De Bruyne and Gerritse, 2018). As organizations adopt and follow these consultancy discourses, they tend to deploy new technologies alongside new workspaces and work organization (De Paoli et al., 2013; Jemine, 2017). As a consequence, could it be more appropriate to conceptualize the evasively labelled "new ways of working" change projects as "triple design" processes, ambitioning to redesign architectural spaces, organizations, and technological equipment at the same time? This paper aims to answer this question by identifying the tensions and controversies that arise when organization, space, and technology are being redesigned simultaneously, and by addressing the challenges of such processes for project management.

Surprisingly, triple design processes have received limited scholarly attention so far, despite their fast-paced development in various economic sectors (Chan et al., 2007; Kingma, 2018). Whereas an abundant literature has respectively addressed space design (e.g. Kornberger and Clegg, 2004), organization design (e.g. Starostka, 2015), and technology design (e.g. Ribes and Finholt, 
2009), few studies have empirically explored projects combining these three objects of design together, and processes through which they are conjointly shaped. Yet, multiple calls have been made for, on the one hand, developing more empirically informed research on design processes (Våland and Georg, 2014), and, on the other hand, integrating the diverse approaches interested in design (Buchanan, 2008; Chan et al., 2007; Taylor and Spicer, 2007). First, in order to better establish triple design processes as a research object, relevant literature to organizational, spatial, and technological design is reviewed. Second, as the paper is based on a qualitative study, the methodological principles supporting data collection and analysis are described. Third, a triple design process is investigated in a media company that initiated a project of "New Ways of Working" including a headquarters relocation, the development of a new organizational structure, and the deployment of innovative technological tools. The emphasis is placed on designing, that is, on the political process through which managerial work is carried out with the explicit aim of improving the organization and shaping its future (Dunbar and Starbuck, 2006; Rylander Eklund and Simpson, 2020).

\section{From design to triple design}

While studies of "triple design" processes are still scarce, there are plenty of arguments in the literature suggesting that organization design, space design, and technology design 1) play a significant role in organizational life and 2) involve intense managerial and political work aimed at resolving and prioritizing controversies and tensions, at making sense of uncertain situations, and at making decisions. In this section, we review the main findings of these three bodies of literature, by emphasizing how they may contribute to the development of a more comprehensive view of triple design processes. Then, the political nature of triple design processes, as well as the underlying challenges in terms of project management, are gradually highlighted. On these grounds, a methodological approach for researching triple design processes is developed.

Organization design is a research object that has a longstanding tradition in organization studies (Buchanan, 2008; Dunbar and Starbuck, 2006; Galbraith, 1974; Mintzberg, 1980; Pfeffer and Salancik, 1977). This is perhaps best illustrated by the special issue of Design Issues entitled "Design and Organizational Change" back in 2008, or by the creation of a dedicated journal, the Journal of Organization Design, in 2012. Authors have referred to "organization design" in at least three distinctive ways. For partisans of the "design school" (Ansoff, 1991), organization design describes a fixed set of elements characterizing organizations, such as work division, firm structure, and coordination mechanisms (Alberts, 2012; Burton, 2013; Mintzberg, 1980). In that perspective, organization design may be seized by means of rigorous analysis or a diagnosis (Mintzberg, 1980). According to a second group of authors, design is a science or a discipline of its own (Cross, 2001; Simon, 1988), of which the tools and methods may be transferred to organizations in order to solve specific problems (Auernhammer and Leifer, 2019; Elsbach and Stigliani, 2018). Research on "managing as designing", on "design attitude", and on "design thinking" suggests that design entails specific modes of cognition and practices that could (and/or should) be implemented in organizational contexts (Boland et al., 2008; Starostka, 2015; Wastell, 2014; Yoo et al., 2006). Such 
contributions build on an opposition between managers and designers, and argue that the first should seek inspiration from the second, who have mastered specific sets of skills such as creative thinking, continuous experimenting, and user empathy (Brown and Katz, 2011; Starostka, 2015; Yoo et al., 2006). Design, it is argued, could hence lead to develop "more human-centered organizations" (Auernhammer and Leifer, 2019, p. 1208). Nevertheless, due to the growth of major design consulting firms, "design thinking" has progressively turned into a management fad conveying overoptimistic techniques and methods related to design (Deserti and Rizzo, 2014; Wastell, 2014), which calls for caution when it comes to consider design thinking in a research perspective.

A third category of scholars have been exploring the influence of design processes on organizational life and their role in organizational change (Buchanan, 2008; 2015; Deserti and Rizzo, 2014). Following Boland and colleagues' call to view design "as a becoming and unfolding process" rather than "a completed and whole thing" (2008, p. 11), studies have investigated the work done by actors to reshape organizations' culture, structure, and practices through strategy adoption, decision-making, discovery, and vision creation (Buchanan, 2008; Dunbar and Starbuck, 2006). Here, organization design (or designing) is understood as a process through which actors develop innovative solutions that challenge the established order and shape new organizational forms (Deserti and Rizzo, 2014; Elsbach and Stigliani, 2018; Visscher and Visscher-Voerman, 2010). Such a process is not managed by an "omnipotent designer", but rather entails collective work performed by a larger variety of stakeholders (Bjögvinsson et al., 2012: 101). In that sense, designing organizations is likely to arouse political controversy (Dunbar and Starbuck, 2006).

Space design has also generated its fair share of academic interest (De Vaujany and Vaast, 2013; Kornberger and Clegg, 2004; Taylor and Spicer, 2007; Våland and Georg, 2014). It is now widely acknowledged that space design is a contemporary management challenge for many organizations (Kingma, 2018; Våland, 2006) which may be turned into a powerful tool for supporting cultural and organizational change (De Paoli et al., 2013; Kornberger and Clegg, 2004; Markus and Cameron, 2002). Research on space design features the same divides as research on organization design between studies of space design on the one hand and studies of space designing on the other. In the first perspective, it is assumed that firms adopt specific kinds of workspace designs, which can be described and classified with regard to characteristics such as their openness, the physical separations, and the dedication of desks (Coradi et al., 2015; Greene and Myerson, 2011). Typologies of workspace designs are widely used by architects, spatial planners, and designers, as it might provide them with valuable insight to align space types and users' preferences (Hua et al., 2010; Thoring et al., 2018). The process of designing itself receives limited attention, as it merely aims to "seek alignment or fit with the existing business and objectives of the organization" (Chan et al., 2007, p.7). Conversely, studies of space designing are interested in developing a dynamic perspective on how organizational spaces are planned, produced, and implemented (Taylor and Spicer, 2007). For these studies, a building "is not a static object but a moving project" that brings together conflicting demands, legal constraints, budget options, and rational actors (Latour and Yaneva, 2008, p. 80). Within this process-oriented perspective, it is once again possible to distinguish between a managerial-oriented, 
prescriptive stream of research, which has attempted to demonstrate how space design processes could lead to added business value (De Paoli et al., 2013) or increased performance (Kim, 2014), and a more analytical and political literature on space design processes. The latter is rather concerned with the challenges of conceiving new workspaces, such as ordering human activity and organizing flows (Kornberger and Clegg, 2004; Taylor and Spicer, 2007), planning in situations of uncertainty and ambiguity (Våland and Georg, 2014), measuring and visualizing future spatial settings (Harty et al., 2015), and collaborating with external actors such as architect teams and designers (Våland, 2006). Overall, it is now commonly admitted in the literature that space design processes inevitably blend architectural concerns with power relations (Kornberger and Clegg, 2004).

Technology design constitutes the third component of "triple design processes", and is also supported by a wide-ranging, although disparate literature (Boland et al., 1994; March and Smith, 1995; Pipek and Wulf, 2009; Ribes and Finholt, 2009). As with organization and space design, there have been attempts to develop static models and typologies of technology design, to assess a firm's "technological maturity" (e.g. Kyriakidou et al., 2013), or to measure the "technological fit" or "alignment" between an organization and the devices or IT solutions being deployed (De Haes and van Grambergen, 2009; Pipek and Wulf, 2009). However, process research and dynamic perspectives on technology design have generated their fair share of scholarly interest. A distinction can once again be made between prescriptive and descriptive approaches of technology design processes, which have been built in opposition to each other (March and Smith, 1995). Proponents of the first approach have developed various arguments for promoting design thinking and design "science" in technology and information systems design processes (Hevner et al., 2004; Zimmerman and Forlizzi, 2008). This has notably resulted in the development of consulting models and recommended practices such as "scrum development" and "rapid conceptual prototyping" (Leifer and Steinert, 2011), as well as in attempts to "predict the potential success of new (...) tools based on how designerly they are" (Stolterman, 2008, p.56). Conversely, as far as descriptive or "pluralist" (McKay et al., 2012) approaches are concerned, research on technology design processes has notably highlighted the challenges of scoping new products (Orlikowski, 1992; Pipek and Wulf, 2009), of continuous corrections and reevaluations (Pipek and Wulf, 2009), and of bricolage and improvisation practices (Boland et al., 2008). It could be argued that the literature on IT development and einfrastructure design is now quite comfortable with the idea that technology design is a political process made of struggles, challenges, and tensions (Ribes and Finholt, 2009).

\section{Towards a political and integrated view of triple design processes}

The literature review reveals that design studies have traditionally been divided between 1) a content-based approach that views design as a set of stable properties of organizations, 2) a prescriptive, process-based approach optimistically depicting design as a creative and promising set of practices for managers, and 3) a descriptive, process-based approach in which design is a political process made of tensions and controversies. These three research perspectives are summarized and exemplified in the table below. 


\begin{tabular}{|c|c|c|c|}
\hline Theoretical perspective & ORGANIZATION DESIGN & SPACE DESIGN & TECHNOLOGY DESIGN \\
\hline $\begin{array}{c}\text { P1: Design as a set of } \\
\text { fixed and measurable } \\
\text { parameters }\end{array}$ & $\begin{array}{l}\text { Parameters characterizing } \\
\text { organizations: job } \\
\text { specialization, behavior } \\
\text { formalization, unit } \\
\text { grouping, liaison devices... } \\
\text { (Mintzberg, 1980) }\end{array}$ & $\begin{array}{c}\text { Parameters characterizing } \\
\text { workspaces: degree of } \\
\text { enclosure, interpersonal } \\
\text { distance, workspace size, } \\
\text { openness, density, } \\
\text { accessibility... (Hua et al., } \\
\text { 2010) }\end{array}$ & $\begin{array}{l}\text { Parameters characterizing } \\
\text { technology: product } \\
\text { innovativeness, uniqueness, } \\
\text { development complexity, } \\
\text { radicalness... (Garcia \& } \\
\text { Calantone, 2002) }\end{array}$ \\
\hline $\begin{array}{c}\text { P2: Design as added- } \\
\text { value practices and } \\
\text { activities }\end{array}$ & $\begin{array}{c}\text { Key assets of "design } \\
\text { thinking" for organizational } \\
\text { change: increased } \\
\text { performance and } \\
\text { innovativeness, more } \\
\text { human-centered culture } \\
\text { (Starostka, 2015) }\end{array}$ & $\begin{array}{l}\text { Key assets of "design } \\
\text { thinking" for space design: } \\
\text { added business value, } \\
\text { increased task } \\
\text { performance, workers' } \\
\text { productivity and } \\
\text { psychological comfort } \\
\text { (Vischer, 2006) }\end{array}$ & $\begin{array}{c}\text { Key assets of "design } \\
\text { thinking" for technology } \\
\text { design: better } \\
\text { understanding of the } \\
\text { customer needs, increased } \\
\text { adoption likelihood, } \\
\text { increased performance of } \\
\text { design teams (Leifer \& } \\
\text { Steinert, 2011) }\end{array}$ \\
\hline $\begin{array}{l}\text { P3: Design as a political } \\
\text { process of tensions }\end{array}$ & $\begin{array}{l}\text { Key tensions of } \\
\text { organization design } \\
\text { processes: conflicting } \\
\text { interests, vision alignment, } \\
\text { resistance to change } \\
\text { (Buchanan, 2008) }\end{array}$ & $\begin{array}{c}\text { Key tensions of space } \\
\text { design processes: ordering } \\
\text { human activity, organizing } \\
\text { flows, planning the future, } \\
\text { visualizing future spatial } \\
\text { settings (Kornberger \& } \\
\text { Clegg, 2004) }\end{array}$ & $\begin{array}{l}\text { Key tensions of technology } \\
\text { design processes: } \\
\text { information imbalance, } \\
\text { recursivity, scoping, users' } \\
\text { acceptance (Pipek \& Wulf, } \\
\text { 2009) }\end{array}$ \\
\hline
\end{tabular}

Table 1: Nine ways of conceptualizing design

This comparative table suggests that the first set of studies (P1) fails to conceptualize design as an ongoing and dynamic process (Boland et al., 2008; Yoo et al., 2006). While another set of studies (P2) acknowledges the processual dimension of design, it appears to build mostly on a "loosely labeled box called design thinking" (Leifer and Steinert, 2011, p.152) and to lack critical and reflexive distance towards the managerial construct or the "fad" that is design thinking (Deserti and Rizzo, 2014; McKay et al., 2012; Wastell, 2014). As a consequence, the present paper aims to build on the processual and political conceptualizations of design processes (P3). A central argument in that regard is that the political dimension of design is not always recognized in studies of design processes, despite multiple promising conceptualizations of design as conflictual processes involving power games and bargaining (Dunbar and Starbuck, 2006; Pfeffer and Salancik, 1977; Ribes and Finholt, 2009; Welsh and Slusher, 1986). Consequently, this paper adopts a processual and dynamic view of triple design processes, which fits with Buchanan's call to "explore design practices" (2008, p.5), while remaining cautious towards the zeal generated around design thinking (JohanssonSköldberg et al., 2013), and while acknowledging the diversity of interests and rationalities underlying design processes (Pfeffer and Salancik, 1977).

\section{Triple design and project management}

Additionally, there are good reasons to think that triple design may have its own challenges in terms of project management. If we acknowledge that design is a political process "filled with contradictions and dilemmas" (Pfeffer and Salancik, 1977, p. 21) or "tensions" (Ribes and Finholt, 2009), we may wonder how these contradictions and tensions are being managed and handled 
within organizational contexts. It is therefore not surprising that the project management literature has paid sustained attention to design-related questions, recognizing that a better understanding of design processes could help managers to deal with them (Aubry and Lavoie-Tremblay, 2018; Dijksterhuis and Silvius, 2017; Lenfle, 2012; Mahmoud-Jouini et al., 2016). The literature emphasizes three main characteristics of design processes that have a direct impact on project managers' practices and on project management theorization: the magnitude and complexity of design projects (1), the generative nature of design (2) and the messiness of designing (3).

Since they encompass organizational change, new workspaces conception, and technological evolutions, triple design processes are by definition large-scale transformation projects that involve considerable resources and unfold over a long period of time. Therefore, as emphasized by Aubry and Lavoie-Tremblay (2018), design processes call for collective and sustained efforts which require slow and reflexive project management approaches. Instead of building on day-to-day control, planning, and orderliness, complex design projects call for exploration, risk-taking, and strategy formulation (Buchanan, 2015; Mahmoud Jouini et al., 2016; Pfeffer and Salancik, 1977; Starostka, 2015). The project management literature notably emphasizes the necessity to think of the project itself as an "unfolding journey" (Rylander Eklund and Simpson, 2020) in which the project manager has to develop lasting trust among project-team members (Lohne et al., 2017). Many authors concur with the idea that the complexity of design processes challenges the rational and instrumental assumptions which have historically supported the foundations of project management (Lenfle et al., 2016; Mahmoud-Jouini et al., 2016; Rylander Eklund and Simpson, 2020).

Moreover, a particularity of design processes is that they are generative in nature, meaning that they permanently grow in size and complexity as new problems are raised, new actors are involved, new decisions are made, new events arise, and new solutions are offered (Lenfle, 2012). Design processes are characterized by a triple uncertainty that concerns the unpredictable consequences of the choices being made, the unclear future preferences and goals of the actors involved, as well as a lack of clarity regarding the framing of the process itself (Sarasvathy et al., 2008). That makes designing a highly-iterative process of which the management is expected to be complex (Aubry and Lavoie-Tremblay, 2018; Chan et al., 2007). Project managers have to deal with the perpetual expansion of the design process by redefining problems at hand, by managing overflows, and by operating within contexts of high uncertainty (Dijksterhuis and Silvius, 2017; Mahmoud-Jouini et al., 2016). It has been increasingly argued that traditional methods of project management, anchored into control-based tools and project planning mechanics, would yield poor results in uncertain and generative contexts (Lenfle, 2012; Mahmoud-Jouini et al., 2016; Picciotto, 2019), which call for new ways to conceptualize generative design processes and their implications for project managers.

It follows from their complex and generative nature that design processes are open-ended and messy, which leaves room for power games and negotiation or even sabotage (Lohne et al., 2017; Stolterman, 2008). Managers of complex design projects may face self-interested, ambiguous and opportunistic behaviors from a multiplicity of stakeholders, including their own team members; 
in short, complex design processes are characterized by divergence (Lenfle, 2012; Pinto, 2014). In that perspective, project managers may spend considerable time dealing with conflicting views and trying to reach consensus (Pinto, 2014). Moreover, they are likely to find themselves caught in ethically challenging situations in which they have to mediate between parties with different interests and goals (Lohne et al., 2017). Curiously, while power dynamics between projects' stakeholders have been acknowledged as a major factor of project success (Davis, 2014), there are relatively few studies in the project management literature that have undertook to theorize power and politics in design processes. With regard to these observations, this paper aims to shed light on the particular implications of triple design processes for project management theory and project managers' practices.

\section{Methodology}

\section{Data collection}

The authors conducted an ethnographic case study in a European media company - further referred to as "EMC" - that initiated a project of "New Ways of Working" involving 1) the design of and the relocation to a new building, 2) an overhaul of their main technological systems, and 3) a redefinition of the organizational culture, modes of governance, and work practices. The project and its design process were mainly handled by two groups of actors: the executive board of EMC, responsible for making the strategic decisions, and a dedicated group in charge of designing and developing the contents of the change - hereafter called "the Taskforce". As the executive board primarily remains a decision-making organ, most of the preliminary debates related to the triple design process took place at the Taskforce level. As a consequence, most of our attention was directed towards the work performed by the Taskforce members. Complete company access has been described as vital to successfully conducting a single case study research (Kelliher, 2011). Following negotiations with the HR Director of EMC, the authors were granted access to all strategic meetings of the Taskforce, and later received the permission for meeting individually with members of the executive board, including the General Administrator of EMC.

Case studies have been described as a useful tool for studying design processes (Breslin and Buchanan, 2008). To ensure data reliability and validity, the conduct of a single-case study ideally requires a variety of data collection techniques to document the events as completely as possible (Kelliher, 2011). Empirical data was collected among the Taskforce and the executive board in two different rounds, using various qualitative methods. At first, the authors conducted non-participant observations of the Taskforce meetings for a period of nine months (from September 2016 to May 2017). These meetings were organized on a weekly basis. The Taskforce members quickly accepted the first author of the paper as an "uninvolved observer" of their endeavors. In the process, various internal documents were also collected, including architectural plans (13), PowerPoint presentations related to the tasks to be performed or to the project organization (9), schedules and timelines (3), and communication plans (2). In a second round, semi-structured interviews were requested with members from the executive board. Five of the nine members of EMC's executive board gave their 
consent for an interview: the General Administrator of the company, the HR director, the IT director, the Real Estate manager, and the transformation project leader. An overview of the data collection process is available in the table below.

\begin{tabular}{|c|c|c|}
\hline & FIRST ROUND & SECOND ROUND \\
\hline TARGET POPULATION & The Taskforce & The executive board \\
\hline PERIOD & September 2016-May 2017 & November 2017 - May 2018 \\
\hline RESEARCH METHODS & $\begin{array}{c}\text { Non-participant observation } \\
\text { Document collection }\end{array}$ & Semi-structured interviews \\
\hline DETAILS & $\begin{array}{c}37 \text { sessions (approx. 120 } \\
\text { hours) } \\
27 \text { internal documents }\end{array}$ & 5 interviews \\
\hline
\end{tabular}

Table 2: Overview of the data collection process

The data collection process favored the observation of the Taskforce meetings as privileged spaces where controversies constitutive of the triple design process were made visible through discourses. Indeed, regular and direct observation of the Taskforce meetings provided specific data that could hardly have been collected using other research methods (Dubois and Gadde, 2002). As far as possible, the original discourses of the actors were carefully documented in the course of the observation process. A reflexive diary (Kelliher, 2011) was used to incorporate the information obtained from the observation sessions, from the documents collected, as well as from the interviews with the members of the executive board.

\section{Data analysis}

Data analysis was performed in two respective stages. A first step in the process consisted in drafting a chronological narrative of about forty pages summarizing the main issues in designing the new building, organization, and technological infrastructure of EMC. Such a narrative used chronology as an ordering device that facilitated a subsequent analytical account of the events (Czarniawska, 1995). The narrative featured a rigorous description of the stages of the design process, and identified the meanings that the field actors ascribed to these stages (Kelliher 2011). However, the narrative approach also left room for unexpected or surprising findings (Czarniawska, 1995; Alvesson and Kärreman, 2007). To the authors, what was striking and could turn into a "potentially interesting" research object in the account of the design process at EMC was the rapid succession and heterogeneity of the issues being brought to the table by the actors (Alvesson and Kärreman, 2007). The narrative illustrated their ambition to redesign their workspaces, their work organization, and their technological infrastructure concomitantly, as well as the challenges of doing so. The field actors appeared to constantly bargain around the object of design that should take precedence, and offered interesting illustrations of a political conceptualization of design processes.

In a second stage of the data analysis process, the focus was set on problematizing moments or plots structuring the narrative through time and space (Czarniawska, 1995). By building strategically organized sets of relations (Doolin, 2003), the authors constructed a second document of interpretative nature to illustrate the emergence of tensions and oppositions feeding the design 
process (Ribes and Finholt, 2009). In total, four overarching tensions were identified in the narrative. The authors further performed a thematic analysis of our account which made visible a series of structuring, political oppositions between the actors around these tensions. Attempts were then made to grasp the underlying rationales and motives of the participants for adopting a given behaviour towards a specific tension in the design process. The thematic analysis was performed under the central assumption that processes of design are fundamentally dynamic, political, and performed by rational actors who are capable of providing explanations and justifications for explaining their actions (Ribes and Finholt, 2009). Therefore, each of the four identified tensions features 1) a position statement or a polarization of the Taskforce members around a given set of issues and 2) a set of bargaining and decision-making moments aimed at overriding them and moving forward with the design process. In the following section, the empirical account is first introduced by detailing the strategic intentions underlying the transformation project of EMC, and then structured around these four key tensions that are simultaneously chronological (they retrace the evolution of the design process through time) and interpretative (they illustrate the emergence of tensions that sustain the design process).

\section{A study of a triple design process: the case of EMC}

From strategic intentions to a large-scale transformation project

EMC is a media company of approximately 2000 workers, which, as a public operator in charge of audio-visual telecommunications, is dedicated to the production and diffusion of media contents. At the time of writing, it has become public knowledge that EMC initiated a large-scale transformation process that includes the construction of a brand-new building, an entire reform of the work organization, and a significant overhaul of their main technologies. However, in order to gather the pieces of the "triple design" process, it is necessary to go back to a series of early events and decisions which, while initially loosely related to each other, were eventually aggregated by EMC's strategic instances into a coherent "transformation program". Historically, the story begins with the decision of the EMC's executive board to reconstruct their headquarters:

"Back in 2012, we [the executive board] raised the question of whether we should renovate our building, which is more than fifty years old now. We did several simulations, and they illustrated that, on a technical, functional, as well as financial level, a new construction project was definitely the best option" (EMC's Real Estate Director)

In addition, the executive board took the decision to commit to an in-depth transformation of their organizational model:

"In 2015, things are going well, our audience ratings are good, we are coming out of a rationalisation plan, finances are all right. So we used this opportunity to take some time to think ahead. [The General Administrator] believed that we had to prepare ourselves for the digital revolution, so we initiated what we called a transformation project" (EMC's Real Estate Director) 
The ambitious scope of the project, as well as the attention given to the digital innovations, made it clear that technological innovations had to be a part of the project:

"In the new building, potentially, all existing technologies could be challenged. At the very least, there are plenty of major technological choices that have to be made. For instance, regarding full IP production, which is not a fully mature technology yet (...) Data management is a second challenge. We speak of bricks, of spaces, but not about how people will work, what data they will use (...) Automation and machine learning is a third one. Will we still publish articles manually validated by journalists, when we know that machines can do that just as well?' (EMC's IT Director)

The origins of the triple design process came, therefore, from a strategic intention to initiate a large-scale transformation project:

"At the end of 2015, we had the shared conviction that our historical model was coming to an end. And all the projects we had initiated in recent years... were just the premises of something bigger (...) Creating an integrated IT direction, developing a project management methodology, assessing the current health of the organization, merging the technological architectures... All these past and ongoing projects came together, and we decided, as part of our strategic plan, that our organizational model had to change" (EMC's General Administrator)

Early 2016, a dedicated working group named "The Taskforce" was formed to handle the change project. As Figure 1 shows, the Taskforce gathers representatives (mostly direct reports of executive board's members) coming from the major directions of the company, working under the lead of an external consultant, appointed Project Manager. The group was initially charged to handle the evaluation and the selection process of an external architect for the new construction. As soon as the architect firm was selected in June 2016, they began to organize weekly meetings to work on the making of the building in a project-based approach, supported by an external consultant specialized in office design. The study focusses on the work they performed for nine months (from September 2016 to May 2017), with the aim of redesigning the company's space, organization, and technological infrastructure. The account is organized around four problematizing moments structuring the design process. 


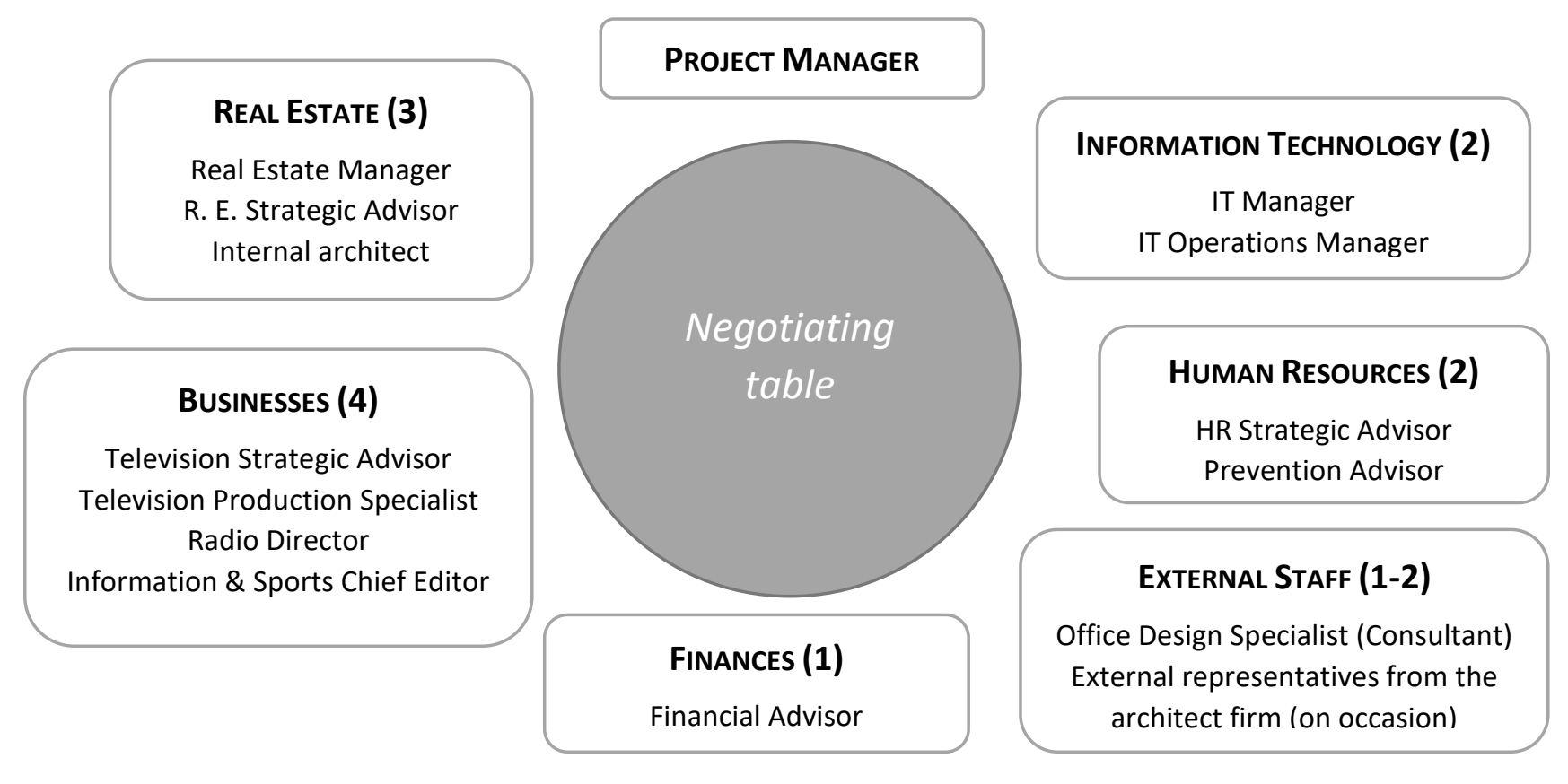

Figure 1: Schematic representation of the Taskforce composition

Making sense of technical uncertainties (Months 1-5)

As the Taskforce began to collaborate with the external architect firm in September 2016, they primarily sought to devise the future building of the company, which was expected to be built by 2022. Over the weeks, technical issues proliferated as the projected infrastructure grew in complexity. It became necessary to make decisions regarding building materials, surroundings, parking options, fire safety, air-conditioning, accessibility, sprinklers, facades, walls, flows, and floors. Dedicated spaces for television and radio activities had to be built with specific constraints regarding acoustic performance, noise insulation, and walls reverberation. The Facilities representatives took the lead of the group as, to fully understand those topics and exchange with the architects, technical expertise was required. They used the building plans provided by the architect firm as a means of delivering stabilized representations of space and a jargon-free translation of the architect language to the other members of the group. However, tensions emerged around the centrality of the technique: the Facilities actively promoted a strictly architectural vision of the design process to which several participants, mainly business representatives, remained reluctant to adhere to. When it came to making decisions that would have concrete impacts on the businesses, these actors began to argue that they "lacked the technical knowledge" to make a stand and that "it was difficult to see the concrete implications of their decisions" (Radio Director). This was notably the case when the discussions began to consider the possibility of mutualizing the media studios of the departments:

Real Estate Manager: "The executive board is concerned by the size of some floors. Globally speaking, we have more square meters in the new building than now. So, the question is, do we really need those square meters? Can we operate with a single, mutualized, larger studio on the $3^{\text {rd }}$ floor instead of the two that we presently have?"

Television Strategic Advisor: "How could we know that? We have no idea about how we will work in six years!" 
Real Estate Strategic Advisor: "Then we should be as flexible as we possibly can. Flexibility and adaptability is our best bet."

Office Design Specialist: "Well, as long as the question of the amount and the size of the studios is not solved, we cannot move on. [EMC] needs to know what production spaces they want to design in the new building (...)"

Radio Director: "I have the feeling that most of the talk we are having is pointless. Too many variables remain unknown." (Taskforce meeting, Month 2)

Uncertainties about how the company would operate in the future, and about how space should be designed as a consequence, began to cripple some Taskforce members - mainly businesses representatives, HR advisors, and the Project Manager - who became reluctant to commit to constraining architectural choices. The Project Manager himself stated that "the Taskforce should avoid making precipitated decisions, especially on such serious matters". As a result, tensions arose between the architect firm and the Taskforce. The architect firm warned the Taskforce that the project would fall behind if the information they were asking for was not delivered in time. The Real Estate architect further insisted on the necessity to "respond to the architects so that the project could move forward". To overcome the problem, the Project Manager asked the executive board to take a clear and final position on a series of issues and to choose between several projective scenarios for the new building. For instance, the executive board agreed on a clear strategy of mutualizing studios between TV, radio, and news departments. Moreover, it was decided that the new workspace had to remain as flexible as possible, in order to accommodate the subsequent choices that would be made in the design process.

Embedding social constraints (Months 3-5)

All of a sudden, as the discussions related to the new building were finding a second wind, an unexpected item turned up on the Taskforce's agenda. A barometer recently produced by a consultancy firm commissioned by the board revealed a shared feeling of unhappiness among EMC's staff. The report was given serious consideration by the members of the board:

"The barometer revealed that our economic indicators were excellent, but our social indicators were far, far from that (...) Well-being, satisfaction at work, management approval (...) So my aim became to use the transformation project to generate a cultural change in a governance structure which is obviously deficient" (EMC's HR director)

"This is a crucial issue. 52\% of our expenses are personnel expenditures. As we are in a creative business, people are our first asset. So if they are not motivated, if they do not adhere to the transformation, we are in trouble" (EMC's General Administrator)

The Project Manager was explicitly asked by the board to tackle the social issues highlighted by the barometer within the Taskforce. Already convinced that "the new building was a critical opportunity to promote a cultural change", the Project Manager immediately stated to the group that the consultants who wrote this report were "no rookies" and that their conclusions "should not be 
taken lightly". He enrolled other participants, such as the HR Strategic Advisor, who agreed that "the new building should not be a building project only", and that measures had to be taken to respond to the barometer. The nature of the work performed by the group began to shift, as it suddenly became imperative not only to envision architectural spaces but also to reflect on the desired cultural changes and to design "new ways of working". The Project Manager set new priorities for the group: elaborating a communication plan in order to share information about the project with the entire workforce; performing a detailed analysis of the users' needs to determine the working spaces required for the new building; involving employees in the process through the development of participatory approaches; and developing a vision, in the form of "leading principles", that would provide a clearer direction to the design process.

These leading principles, validated and endorsed by the executive board, were structured around four dimensions: the work environments, the work tools, the corporate culture, and the company's brand. These principles materialized a series of directions specifying the content of the change to come, and, consequently, impacted the design process and the work performed by the Taskforce. They notably stated that the new building would "include shared, flexible, and ergonomic workspaces", that innovative tools should "allow remote working formulae, mobility, and virtual presence", that communication has to be "genuine and transparent", that management should become "solution-oriented and objective-oriented", and that governance had to be "exemplary" (excerpts from an internal document). However, once again, doubts were expressed regarding the appropriateness and the desirability of some measures. The implementation of non-attributed desks in the future building became a central point of discussion:

IT Manager: "Do we finally know if we plan to go NWoW and have flexible desks, or not? This question will have to be answered sooner or later."

Office Design Specialist: "We are currently working on the basis of a ratio of nine desks for ten people, but this is a hypothesis that has not been verified yet."

IT Manager: "Yes, but are we sure that the company wants to take this direction?"

Real Estate Manager: "From what I understood, this seems to have been validated by the executive committee. They are willing to consider options of desk optimization."

Television Strategic Advisor: "This is concerning. People will be extremely worried about this. We have to be really careful" (Taskforce meeting, Month 4)

Over the weeks, a fracture line gradually surfaced between promoters of a "soft" conception of the design process - for whom the primary object of design was a cultural and organizational change - and experts defending a "hard" version of the design process - oriented towards the technical and material dimensions of the new construction. For several weeks, the Project Manager had been able to take the lead of the group and initiate several actions in terms of vision definition, communication, and change management. However, members of the Taskforce began to express their concern that the project "was going nowhere" and that "time was being wasted" because "blueprints had not been discussed for two months" (Television Production Specialist). 
It should be recalled at this point that the Project Manager was an external consultant who had no particular knowledge neither of the media sector nor of architecture: he was appointed at this position by the executive committee for his expertise in organizational change and social dialogue. More specifically, by appointing an external Project Manager, the executive committee had wanted, first, to avoid internal tensions and competition for the position, and second, to make sure that the project would not be limited to the construction of new headquarters, but would also involve a transformation of the organization. Although the Project Manager had managed to turn the Taskforce into a constructive discussion space, his appointment had been welcomed with some scepticism and his legitimacy had so far remained subtly contested - especially from the real estate representatives, who were initially yearning for the project management role.

The contestation had so far remained mostly latent, but when some members of the Taskforce realized that the Project Manager was delaying the construction agenda by giving priority to the organizational transformation, they began to voice their concerns. The Project Manager realized that he was at risk of damaging the Taskforce' constructive dynamics, and offered that the Taskforce meetings would now be co-organized with the Real Estate Manager. As a consequence, meetings soon became split in two moments, each of them being organized around a dominant conception of the design process ("soft"/"hard") and around different actors (the Project Manager, HR advisors, and the external consultant one the one hand, and Real Estate representatives and architects on the other). This move was positively welcomed by everyone and allowed the Project Manager to restore an equilibrium between both sides.

\section{Deploying participatory approaches (Months 5-9)}

At the beginning of Month 5, another incident rattled the progression of the Taskforce. The executive committee met with the architect firm and validated a series of technical options that had not previously been discussed nor supported by the Taskforce. Some of the decisions that were made even went directly against the Taskforce's conclusions. Members of the Taskforce immediately argued that the directors were "not respecting the cultural and governance change that they wanted to promote" (IT Manager) and that "decisions had been made too quickly by an executive committee seldom informed" (Information and Sports Chief Editor). Moreover, they pointed out that this episode would "undermine the Taskforce legitimacy in the eyes of the architects" (Real Estate Manager). Unanimously, the members of the Taskforce, realizing that they were not always consulted when it came to decision-making, questioned the vacuity of the work they were accomplishing. Why were they collectively solving problems and questions related to the future building, while decisions were taken at the highest level of the organization without involving them?

The Project Manager seized this momentum straightaway, arguing that he was the one who had the difficult responsibility to raise the awareness of the executive committee members on such matters. The directors, he claimed, were not used to "work collaboratively" and had to learn "how to delegate". According to him, whereas the Taskforce had succeeded in overcoming the "silo logic" (whereby everyone would favour the interests of its own department first, at the expense of 
collaboration), the executive committee remained divided by "divergent points of view" and "had to evolve" (Project Manager). Promoting inclusive and participatory approaches, he concluded, had to become a key objective of the Taskforce. To achieve this, the project manager came up with a precise plan. He suggested creating five subgroups, each of these being led by a member of the Taskforce and "sponsored" by a member of the executive committee (see Figure 2). He argued that this was an efficient way to structure the activities of the Taskforce, involve more representatives from the workforce, and increase awareness among the executive committee. Instead of condensing all the preliminary works into the hands of the Taskforce, it would from now on be delegated to specialized subgroups, each of them with their own project manager.

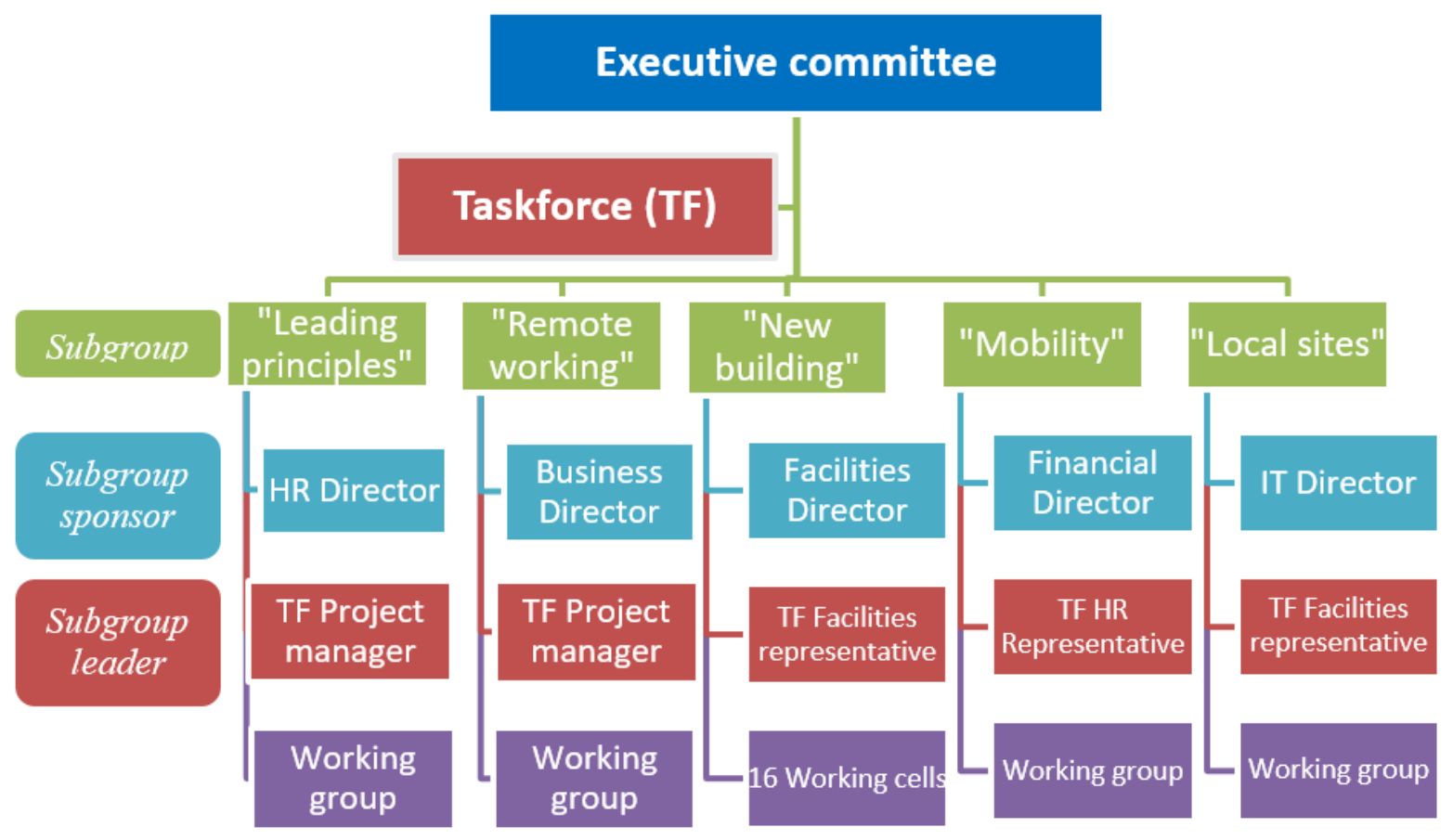

Figure 2 - Representation of the subgroups structure as suggested by the Project Manager

The idea was positively welcomed by the Taskforce members who saw an opportunity to facilitate the work of the Taskforce. Very quickly, the subgroups structure became a depiction of the various logics and interests of the actors involved in the design process. Gathering proponents of a "hard" conception of the design process and operating under the lead of the Real Estate Manager, the generic subgroup "new building" was further split into several technical cells in charge of technical matters (such as "fire safety", "logistic spaces", "security", "special construction techniques", and so on). Under the lead of the Project Manager, the subgroup "Leading Principles" became charged with developing the vision guiding the transformation project, and the subgroup "Remote working" began to develop a homeworking pilot project. Although less significant, issues related to mobility (i.e. parking design and alternative commuting) and the coordination with local sites were also delegated to two dedicated subgroups supervised by Real Estate representatives. Executive committee's members ultimately recognized the merit of such a participatory approach: 
"There have been misunderstandings, for instance of what the Taskforce meant, and of how to work together with them. Some members of the executive committee did not understand immediately, and we assumed some rights that we did not have (...) Now, I think that all of us are well aware that the Taskforce exists, which does not mean that the executive committee will follow each of their recommendations all the time. It's not because you speak of a more participatory governance that official instances of decision suddenly cease to exist (...) But we definitely learned to give more consideration to the arguments brought to the table by the Taskforce" (EMC's HR Director)

Tensions over architectural and social priorities gradually decreased during the Taskforce meetings, as the design processes were now handled by dedicated subgroups. The role of the Taskforce increasingly evolved towards coordination and direction-providing, rather than exploration and debate. Moreover, the crystallization of the subgroups as represented in Figure 2 made it clear that decisional power, while ultimately in the hands of the executive committee, had now to rely on the work conducted by a myriad of actors involved in the subgroups and supervised by the Taskforce.

Facing technological uncertainties (Months 6-9)

The inclusion of new actors from all kinds of departments and hierarchical levels in the subgroups also forced the Taskforce to include new issues and challenges in the design process. Among the unexpected elements brought to light by these new players came the question of the technological feasibility of the project. During a meeting of the "Leading Principles" subgroup, representatives from business departments - TV, radio, news, and e-news - and from support ones - HR, finances and facilities - opened a critical reflection of the IT tools at their disposal. They voiced significant discontent regarding the systems they worked with, described as "slow, outdated, and inadequate" (HR Team Manager). The majority of them expressed ambitious technological needs for the future such as "working without paper", having "electronic signature", "appropriate communication tools", "disconnection rights", "online support", and "performing software" (Observation notes). They questioned the capability of the IT department of EMC to "implement the tools of the future before the construction ends" (Radio manager).

Two weeks later, another controversial episode involving technological opportunities occurred. The "Mobility" subgroup, in charge of rethinking the mobility policies of EMC, had spent several weeks exploring web-based solutions that could be used by the company to manage the reservation of parking spots near the future building. However, all of the preselected applications were turned down by the Security Officer of the IT department, on the grounds that none of them appeared to respect the security norms in effect at EMC. The leader of the Mobility subgroup immediately regretted that "digital technology [was] evolving much faster than the IT department", and warned that "the close-minded attitude of the IT department had caused a great disappointment among the members of the subgroup". He also demanded an increased involvement of the IT department with the project's subgroups in order to prevent such incidents from happening again. 
At this point, the Project Manager realized that technology-related discussions had, for the most part, remained largely concealed from the perimeter of the Taskforce, and that the IT department had been pursuing its own agenda. When questioned on the matter, the IT representatives in the Taskforce argued that the department had "ongoing internal projects" to develop the IT systems of the company and that it was necessary to delegate technological discussions to specialized IT groups to prevent "unrealistic expectations" from the workers to come in. As a consequence, the work made on technological infrastructures had remained mainly handled by parallel IT working groups, out of the project's structure represented in Figure 2. In the course of Month 7, it was decided by the executive committee that the project group "technological deployment", so far part of the IT direction, would become a subgroup of the transformation project, and that IT representatives would be assigned to other subgroups where they were needed.

As the building permit had to be deposited for the end of Month 10, it became imperative for the Taskforce to reach conclusive agreements regarding the construction plans. The group had to take position on a series of technological options that would have architectural consequences: the space needed for the broadcast wires would determine the height of the flooring; the precise dimensions of the radio antennas had to be known so that the roof of the building would be scaled in consequence; equipping the new building with optic fiber rather than copper wires would imply subsequent costs that had to be planned. However, when the above concerns were relayed to the Taskforce, the IT representatives argued that it was difficult "to know at the present time what technological equipment [would] be needed in several years" (IT Manager):

Real Estate Manager: "There are still pending questions related to space allocation. Well, one of them is about the space dedicated to technical proximity rooms. The more square meters are dedicated to such rooms, the more expensive the project will be."

IT Manager: "Listen. Today, no one, no one knows anything about the technology we will use in five years (...) Should we mutualize these proximity rooms or not, I don't know (...) What I can tell you is, if we keep today technologies... In the currently planned configuration for the new building, I can tell you, none of the studios you plan to have will operate properly."

Internal Architect: "When can we expect to solve the question of the proximity rooms, then? In five years? Because in two months, we have to initiate the tendering process, and we can't postpone this deadline for no reason" (Taskforce Meeting, Month 8)

It is not until the very last weeks preceding the application deadline for the building permit that a compromise was found on the space to be allocated to IT rooms. Although a centralized ICT room was drawn on the plans, smaller "buffer" areas were kept near the studios as a precautionary measure. At the end of the day, the IT Manager heavily relied on the argument of the unpredictability of technological evolutions to preserve a maximum of space dedicated to the IT facilities. The application procedure that was initiated at the end of Month 10 sealed a major step in the design process, as subsequent work done by the Taskforce and the subgroups would from now on be constrained by the choices and the decisions that were inscribed in the building permit record. 


\section{Tensions, twists, temporalities, and arbitration in triple design processes}

As reminded by the literature review, existing studies on design processes have developed a tendency to investigate a specific object of design (organization, space, or technology), hence framing the design process around a predefined object. The argument developed in the present paper is that firms developing "New Ways of Working" kinds of projects are not prone to operate such a framing. On the contrary, organization, space, and technology appear to be mutually and simultaneously redesigned. The case of EMC illustrates that actors involved in the Taskforce consider and prioritize in turn architectural and infrastructural matters, organizational change and governance evolutions, as well as technological innovation. However, the case suggests that these three objects of design are not simply there; rather, they are emerging in the course of the design process itself. The expansion of the design object primarily occurs through political tensions, unexpected twists, conflicting temporalities, and arbitration measures.

First, triple design appears to be a political process made of tensions that involves groups of actors with their own interests, agendas, and strategies. The Real Estate representatives and the architects are primarily concerned with a construction project and its technical implications; conversely, the Project Manager is mandated by the executive committee to address well-being and satisfaction issues and prioritises organizational and governance changes; later on, the project generates strong expectations from the employees regarding technological innovations. The actors involved in the design process participate to its complexification by adopting divergent or even contradictory perspectives on what the object of design should be. Interestingly, these tensions surface in the way the actors designate the project: for some of them, it is a "construction" or an "architectural" project of which the aim is to design "a new building"; others speak of a "transformation project" or of a "new organization"; still others invoke a "brand new technological architecture". It is through these tensions, structured around political agendas, that the object of the design process expands and gradually becomes "triple design".

Second, the case of EMC reveals a series of unexpected twists that participate to the complexification of the object of design. The Taskforce is regularly interrupted in its course by precipitating and unpredictable events. Ambitious perspectives of mutualizing studios slow down the discussions with the architects; a commissioned barometer suddenly appears on the agenda; the executive committee make controversial decisions that question the role of the Taskforce; the users involved in the work groups voice strong concerns regarding their IT systems; technological uncertainties delay the construction agenda. These twists fuel the existing tensions and trigger opportunistic behaviors. For instance, the business representatives refuse to make constraining decisions of space occupation, and the HR representatives use the barometer as an argument to add social matters to the Taskforce's agenda. These twists are largely out of the control of any member of the Taskforce, and rather appear as imponderables that have to be dealt with. Yet, they play an important role in the evolution of the design object: the barometer of the consultancy firm triggers the strategic reflection around cultural change, and the users' unexpected critiques foster a technological perspective on the design process. 
A third finding suggests that the visible tensions related to the object of design are further articulated around two distinct temporal orientations, which we labelled "project time" on the one hand, and "projected time" on the other. Disagreements that arise in the triple design process are not merely about the prevalence of one object of design over another; they also oppose short-term and project-related concerns with longer-term aspirations. In the course of the design process, some actors invoke a project-oriented logic that emphasizes deliverables, short deadlines, and a formal timeframe that has to be followed ("project time"). Others argue on the grounds of sustainability and continuity instead, recognizing that decisions made today are bound to have a lasting impact on the company's personnel and consequences that will outlive the project itself ("projected time"). While the first temporal logic of action call for making decisions and going forward, the second one favour caution and longer-term thinking and planning.

Finally, the case emphasizes various practices of "arbitration" deployed by the Project Manager to overcome the tensions and to incorporate conflicting temporalities into the design process. Following the injunction to integrate the results of the barometer into the Taskforce's scope of action, the Project Manager establishes "leading principles" for the project that include governance and cultural change. When the group faces a frustrating episode of unilateral decisions made by the executive committee, the Project Manager decides to initiate working groups. As the participants to these groups express strong needs and expectations regarding the IT systems, the Project Manager chooses to integrate the IT working teams within the project's structure. Arbitration is primarily performed by the Project Manager, as he is the one who often finds compromises in the negotiations and who structures the project so that the various objects of design may be worked on appropriately.

Figure 3 offers a visual representation of the triple design process at EMC. It accounts for the temporal orientations (project time and projected time), for the existing tensions (the six conceptions of the design object and objectives assigned to the project by the actors involved), as well as for the twists (in black) and the arbitration measures (in grey) taken by the Project Manager. We suggest that Figure 3 summarizes the process of expansion of the design object in the course of the project. The initial mission of the Taskforce (working on construction plans) is gradually expanded and increases in complexity as the project moves forward, as twists occur, and as arbitration measures are taken. Expansion is underlined by four mechanisms - tensions, twists, temporalities, and arbitrations - and explains how triple design actually unfolds. 
Deadlines, deliverables, decision-making, short-term results

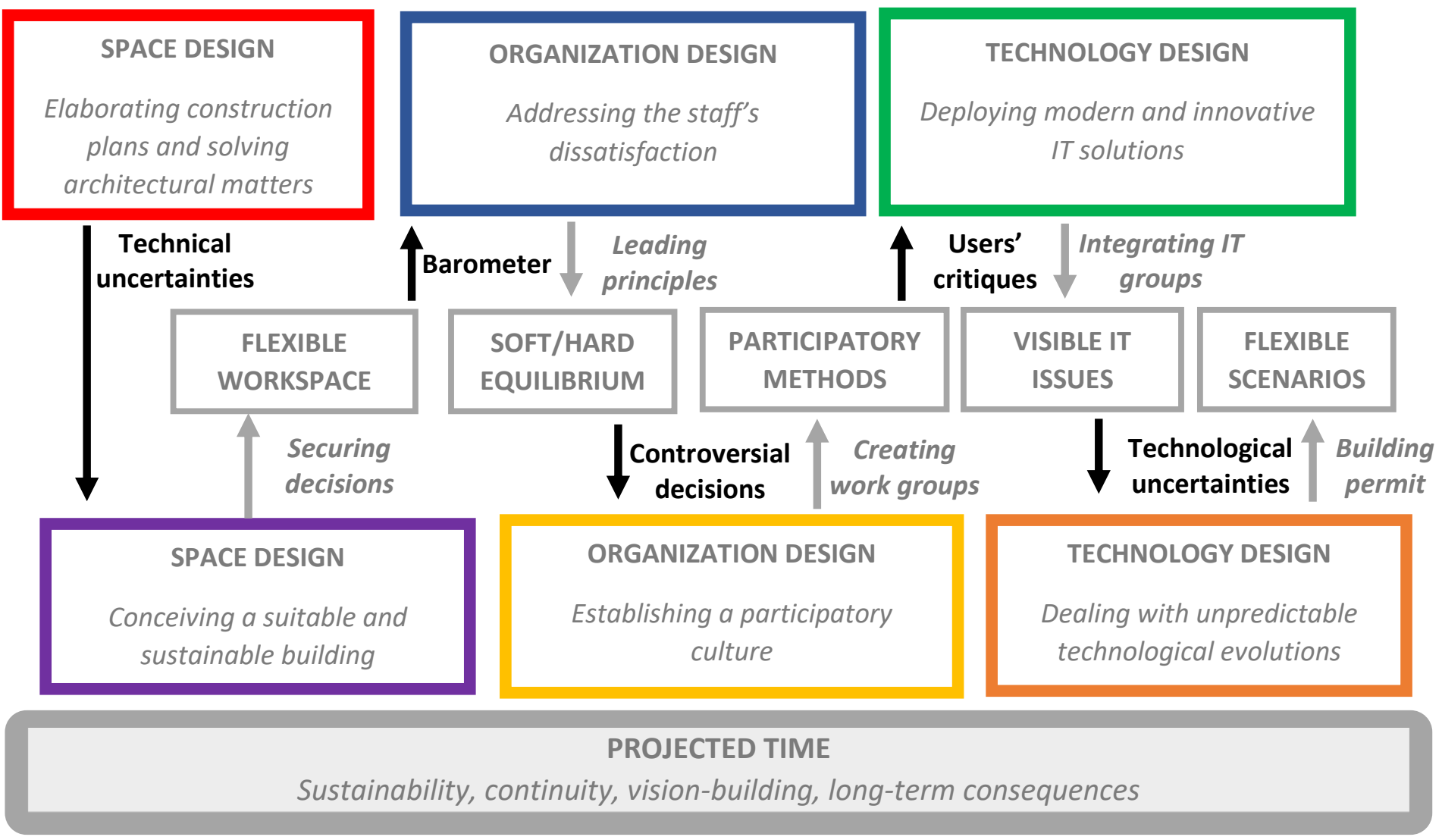

Figure 3: A visual representation of the triple design process at EMC

The main findings of the case can, therefore, be summarized as follows. The design process reveals tensions between conflicting conceptions of the primary object of design (organization, space, technology), as the latter is gradually expanding. In the course of the project, the various actors involved negotiate and argue over the importance and prioritization of these three design objects. Unexpected twists occur and participate to the expansion of the design object as well. In addition, controversies reveal temporal tensions between project time and projected time. Even when the participants agree on the object of design to prioritize, they might defend averse positions as they reason on the basis of a temporal scale that is either the project length, or rather the sustainability and the continuity of what they are designing through the years or decades. Lastly, the case illustrates the measures being taken by the Project Manager to arbitrate between these tensions in order to bring the design process forward. The overall picture of the triple design process at EMC underlines conflicting tensions, occasionally triggered by unexpected twists, structured around various temporalities, which are subject to a necessary work of arbitrage in order to drive the project forward. 


\section{Discussion and implications}

The escalating diffusion of consultancy and managerial discourses promoting "new" forms of organization through catchy labels such as "agile working", "holacracy", "smart working", or "new world of work" has greatly increased the significance of triple design processes for organizations. Indeed, recent studies suggest that space, organization, and technology are more and more designed concomitantly due to the proliferation of "New Ways of Working" projects (e.g. De Kok et al., 2014; De Leede, 2017; Jemine et al., 2019; Kingma, 2018). This paper constitutes an original attempt to use the literature on design on three objects of design that have historically been examined either separately or in pairs (e.g. Våland and Georg's study on space and organization design (2014); Orlikowski and Scott's study on technology and organization design (2008)), while further reflecting on the challenges of such design processes for project managers, who have to handle political tensions, to cope with unexpected twists, and to juggle diverging temporal horizons. In this section, we discuss the implications of the paper for project management scholars and practitioners.

In an academic perspective, it makes little doubt that considering design theory and processes is a promising avenue of research for the project management field, as design processes, due to their complexity, generative nature, and messiness, raise their fair share of challenges for project managers (Lenfle, 2012; Lohne et al., 2017). While design itself has received some degree of interest in the project management literature (e.g. Lenfle et al., 2016; Rylander Eklund and Simpson, 2020; Yap et al., 2017), we argue that triple design processes have remained mostly unexplored so far. Some of the constitutive dimensions of triple design processes have already been granted attention from project management scholars, such as managing a diversity of stakeholders (e.g. Karlsen, 2002), facing uncertainty in early stages (e.g. Kolltveit et al., 2005), and dealing with unforeseen events (Söderholm, 2008). Conversely, other questions raised in the present paper would deserve further research, such as the management of complex transformation projects and of temporalities in tension.

As mentioned in the introduction, transformation projects simultaneously involving space, organizations, and technologies redesign are expected to flourish in the years to come (De Leede, 2017). So far, the existing literature on New Ways of Working has overwhelmingly remained anchored into the idea that such projects entail "3Bs" - Bricks, Bytes, and Behaviors (Baane, 2011; De Kok et al., 2014). These 3Bs have been assumed by organizational actors to be a "methodology" that should guide the implementation of their transformation projects (Jemine et al., 2019). However, while the 3Bs form, at first glance, a convenient framing device for managing a NWoW project, they do not say much about the interconnected design processes supporting such projects, about the political tensions between partisans of one object of design over another, nor about the complexity for project managers to arbitrate between these partisans and to make decisions in the midst of political issues. Our findings, therefore, plead for more empirically-grounded and processual studies of transformation projects in the making, in which challenges for project management are more clearly elaborated. 
Findings also reveal the need to conduct further research on project time and projected time. Time, timing and temporal progress are recurrent concerns in project management studies and have been well discussed in previous works (e.g. Dille and Söderlund, 2013). However, we argue that the structuration of design processes around two temporalities in tension - project time and projected time - has received much less attention. The central question here is to understand the role of time in achieving collective action: participants to the design process are caught in a permanent tension between the "here-and-now" practices of planning and the long-term goals of sustainability and viability (Karasti et al., 2010, p.400). Since their origins, projects have been conceptualized as transitional endeavors, time-limited organizational forms, characterized by shortterm temporalities and deadlines (Jensen et al., 2016). Yet, redesigning organizational structures, spaces, and technologies necessarily call for considering temporal scales that outlive the project itself. Following Ribes and Finholt (2009) we argue that an inherent challenge to triple design processes lies in what the authors have called the "Long Now", that is, in working under today's constraints and assumptions to generate a sustainable future. Further research may be required to better grasp how "infrastructuring" - designing spaces, organizational models and technologies that are intended to stay - occurs within organizational contexts.

The paper raises several practical implications for project management. The study illustrates that triple design processes are first and foremost characterized by unpredictable expansions, which call for adaptations in project management style and techniques. In particular, leading a project team in the midst of political tensions, diverging conceptions of the project purpose, contrasted temporal orientations, and unexpected twists appears to be a daunting challenge for any project manager. Specific attention has to be paid to the political alliances and equilibriums, to the alignment between decision-makers and project teams, and to the constant involvement of the project team members (Hochwarter, 2012). Moreover, the project perimeter and objectives should never be taken for granted, as they appear to be permanently renegotiated by the actors involved in the project teams. These observations imply that project managers would benefit from adopting a less directive, emergent style of project management, axed on information gathering and participative control, rather than a planned style relying on milestones monitoring and directive control (Lewis et al., 2002). It should also be noted that flexibility and openness in early design stages have been shown to result in positive impacts on project performance (Sohi et al., 2019). In sum, triple design processes involve unpredictable expansions which require flexibility and adaptability from project managers.

An additional implication for project managers relates to the centrality of arbitration as a project management practice. Arbitration measures appear to be crucial for the project success, as they allow the gradual expansion of the object of design. This, in turn, suggests that the capability of project manager to identify design-related tensions and to arbitrate between these tensions are key competencies of a "good" project manager (Bredillet et al., 2015). Arbitration involves understanding the controversies at stake and subsequently designing compromises and solutions that overcome these controversies and allow the project to move forward. To that extent, arbitration first requires that the project manager legitimacy is accepted and that some degree of collaboration is reached 
within the project team (Lohne et al., 2017). Arbitration measures are also depending upon the project manager's past experience, creativity, and ability to come up with the most satisfying solutions for a given problem. Ultimately, the present case pleads for considering arbitration as a decisive project management practice in complex design projects, and suggests that the ability to build compromises amidst political tensions and conflicting temporalities is a key expertise for the management of triple design processes.

\section{Conclusion}

The initial aim of the paper was to counterbalance the prescriptive and normative literature on New Ways of Working by developing a better understanding of how such complex projects are gradually structured and ordered in practice. The paper coined the term "triple design" to designate the simultaneous design of a new building, a new organization, and new technologies. The literature review revealed a mismatch between the scientific literature on design on the one hand, which has historically been structured around well-bounded objects of design conceptualized in isolation, and the empirical realities of many organizations on the other hand, who are increasingly confronted with the diffusion of consultancy and managerial discourses promoting ambitious projects of organization, space, and technology redesign at the same time (e.g. the Bricks, Bytes, Behaviors triptych that underlies most projects of "New Ways of Working"). The paper then explored how such a process unfolded in practice through an empirical study of a media company. The case illustrates how the design process generates tensions around the three objects of design and in two temporal perspectives, and emphasizes the progressive prioritization of architectural, organizational, and technological controversies through arbitration measures.

The theoretical originality of the paper lies in breaking down the concept of design in three separate objects - organization, space, and technology - and examining how these objects were conjointly problematized by an organization in transformation. The study, therefore, sheds light on the expansion of the interconnected design processes that support projects of "New Ways of Working", which have received limited scholarly attention so far. The analysis of the design process illustrates four main findings. First, it highlights a series of tensions around the primacy of one object of design over another, which result from political struggles between the participants to the design process. Second, it stresses the role of unexpected twists disrupting the design process and offering new opportunities to the actors. Third, the temporal tensions between project time and projected time in the design process are emphasized. Fourth, the paper shows how the aforementioned tensions are resolved through various arbitration measures. Directions for future research and implications for project managers were drawn from the analysis, as the authors notably suggest conducting further investigations of time and arbitration practices in design processes. 


\section{References}

Alberts, D. (2012), "Rethinking Organizational Design for Complex Endeavors", Journal of Organizational Design, Vol. 1 No. 1, pp. 14-17.

Alvesson, M. and Kärreman, D. (2007), "Constructing Mystery: Empirical Matters in Theory Development", Academy of Management Review Vol. 32 No. 4, pp. 1265-1281.

Ansoff, I. (1991), "The design school: Reconsidering the basic premises of strategic management", Strategic Management Journal, Vol. 12, pp. 449-461.

Aubry, M. and Lavoie-Tremblay, M. (2018), "Rethinking organizational design for managing multiple projects", International Journal of Project Management, 36(1), pp. 12-26.

Auernhammer, J. and Leifer, L. (2019), "Is Organizational Design a Human-Centered Design Practice?", in Proceedings of the Design Society: International Conference on Engineering Design, Delft, 58 August 2019, pp. 1205-1214.

Baane, R. (2011), "Het nieuwe werken ontrafeld : Over Bricks, Bytes \& Behavior", Tijdschrift voor HRM, Vol. 1, pp 7-23.

Bjögvinsson, E., Ehn, P. and Hillgren, P. (2012), "Design things and design thinking: Contemporary participatory design challenges", Design Issues, Vol. 28 No. 3, pp. 101-116.

Boland, R., Tenkasi, R. and Te'eni, D. (1994), "Designing Information Technology to Support Distributed Cognition", Organization Science, Vol. 5 No. 3, pp. 456-475.

Boland, R., Collopy, F., Lyytinen, K. and Yoo, Y. (2008), "Managing as designing: Lessons for organization leaders from the design practice of Frank O. Gehry", Design Issues, Vol. 24 No.1, pp. 1025.

Bredillet, C., Tywoniak, S. and Dwivedula, R. (2015), "What is a good project manager? An Aristotelian perspective", International Journal of Project Management, Vol. 33 No. 2, pp. 254-266.

Breslin, M. and Buchanan, R. (2008), "On the case study method of research and teaching in design", Design Issues, Vol. 24 No. 1, pp. 36-40.

Brown, T. and Katz, B. (2011) Change by design. Journal of Product Innovation Management, Vol. 28 No. 3, pp. 381-383.

Buchanan, R. (2008), "Introduction: Design and organizational change", Design Issues, Vol. 24 No. 1, pp. 2-9.

Buchanan, R. (2015), "Worlds in the Making: Design, Management, and the Reform of Organizational Culture", She Ji, Vol. 1 No. 1, pp. 5-21.

Burton, R. (2013), "The Future of Organization Design: An Interpretative Synthesis in Three Themes", Journal of Organization Design, Vol. 2 No. 1, pp. 42-44.

Chan, J., Beckman, S., and Lawrence, P. (2007), "Workplace Design: A new managerial imperative", California Management Review, Vol. 49 No. 2, pp. 6-22. 
Coradi, A., Heinzen, M. and Boutellier, R. (2015), "A Longitudinal Study of Workplace Design for Knowledge Exploration and Exploitation in the Research and Development Process", Creativity and Innovation Management, Vol. 24 No. 1, pp. 55-71.

Cross, N. (2001), “Designerly Ways of Knowing: Design Discipline versus Design Science”, Design Issues, Vol. 17 No. 3, pp. 49-55.

Czarniawska, B. (1995), "Narration or Science? Collapsing the Division in Organization Studies", Organization, Vol. 2 No. 1, pp. 11-33.

Davis, K. (2014), "Different stakeholder groups and their perceptions of project success", International Journal of Project Management, Vol. 32 No. 2, pp. 189-201.

De Bruyne, E. and Gerritse, D. (2018), "Exploring the future workplace: results of the futures forum study", Journal of Corporate Real Estate, Vol. 20 No. 3, pp. 196-213.

De Haes, S. and van Grembergen, W. (2009), "An Exploratory Study into IT Governance Implementations and its Impact on Business/IT Alignment", Information Management Systems, Vol. 26 No. 2, pp. 123-137.

De Leede, J. (2017), New Ways of Working Practices: Antecedents and Outcomes, Emerald Group Publishing Limited, Bingley.

De Paoli, D., Arge, K. and Blakstad, S. (2013), "Creating business value with open space flexible offices", Journal of Corporate Real Estate, Vol. 15 No. 3, pp. 181-193.

De Vaujany, F. and Vaast, E. (2013), "If These Walls Could Talk: The Mutual Construction of Organizational Space and Legitimacy", Organization Science, Vol. 25 No. 3, pp. 713-731.

Deserti, A. and Rizzo, F. (2014), "Design and the Culture of Enterprises", Design Issues, Vol. 30 No. 1, pp. 36-56.

Dijksterhuis, E. and Silvius, G. (2017), "The design thinking approach to projects", Journal of Modern Project Management, Vol. 4 No. 3, pp. 32-41.

Dille, T. and Söderlund, J. (2013), "Managing temporal misfits in institutional environments: A study of critical incidents in a complex public project", International Journal of Managing Projects in Business, Vol. 6 No. 3, pp. 552-575.

Doolin, B. (2003), "Narratives of Change: Discourse, Technology and Organization", Organization, Vol. 10 No. 4, pp. 751-770.

Dubois, A. and Gadde, L. (2002), "Systematic combining: An abductive approach to case study research", Journal of Business Research, Vol. 55 No. 7, pp. 553-560.

Dunbar, R. and Starbuck, W. (2006), "Learning to design organizations and learning from designing them", Organization Science, Vol. 17 No. 2, pp. 171-178.

Elsbach, K. and Stigliani, I., (2018), "Design Thinking and Organizational Culture: A Review and Framework for Future Research", Journal of Management, Vol. 44 No. 6, pp. 2274-2306.

Fauconneau-Dufresne, S., Jemine, G., Pichault, F. and Rondeaux, G. (2018), "Beyond Flexibility: confronting normative and lived spaces of New Ways of Working", $8^{\text {th }}$ Organizations, Artifacts \& Practices workshop, 20-22 June 2018. 
Galbraith, J. (1974), "Organization Design: An Information Processing View”, Interfaces, Vol. 4 No. 3, pp. 28-36.

Garcia, R. and Calantone, R. (2002), "A critical look at technological innovation typology and innovativeness terminology: a literature review", The Journal of Product Innovation Management, Vol. 19 No. 1, pp. 110-132.

Greene, C. and Myerson, J. (2011), "Space for thought: Designing for knowledge workers", Facilities, Vol 29 No. 1, pp. 19-30.

Harty, C., Tryggestad, K. and Jacobsen, P. (2015), "Visualisations and calculations of spaces: Negotiating hospital design during on-boarding", $31^{\text {st }}$ Annual Association of Researchers in Construction Management Conference, 7-9 September 2015, pp. 875-884.

Hevner, A., March, S., Park, J. and Ram, S. (2004), "Design Science in Information Systems Research", MIS Quarterly, Vol. 28 No. 1, pp. 75-105.

Hochwarter, W. (2012), "The positive side of organizational politics", in G.R. Ferris \& D.C. Treadway (Eds.), Politics in Organizations: Theory and Research Considerations (pp. 27-65). Routledge/Taylor \& Francis Group.

Hua, Y., Loftness, V., Kraut, R. and Powell, K., (2010), "Workplace Collaborative Space Layout Typology and Occupant Perception of Collaboration Environment", Environment and Planning B: Planning and Designing, Vol. 37 No. 3, pp. 429-449.

Jemine, G., (2017), "Using digital devices within new forms of organization: emergence to stabilization", Sociologies Pratiques, Vol. 34 No. 1, pp. 49-59.

Jemine, G., Dubois, C., and Pichault, F. (2019), "From a new workplace to a New Way of Working: legitimizing organizational change", Qualitative Research in Organizations and Management.

Jensen, A., Thuesen C. and Geraldi J. (2016), "The Projectification of Everything: Projects as a Human Condition", Project Management Journal, Vol. 47 No. 3, pp. 21-34.

Jeyasingham, D., (2016), "Open spaces, supple bodies? Considering the impact of agile working on social work office practices", Child and Family Social Work, Vol. 21 No. 2, pp. 209-217.

Johansson-Sköldberg, U., Woodilla, J. and Çetinkaya, M. (2013), “Design thinking: Past, present and possible futures", Creativity and Innovation Management, Vol. 22 No. 2, pp. 121-146.

Karasti, H., Baker, K., and Millerand, F. (2010), "Infrastructure time: Long-term matters in collaborative development", Computer Supported Cooperative Work, Vol. 19 No. 3-4, pp. 377-415.

Karlsen, J. (2002), "Project stakeholder management", Engineering Management Journal, Vol. 14 No. 4, pp. 19-24.

Kelliher, F. (2011), "Interpretivism and the pursuit of research legitimation: an integrated approach to single case design", Leading issues in business research methods, Vol. 1 No. 2, pp. 123131.

Kim, S. (2014), "Physical Workplace as a Strategic Asset for Improving Performance in Public Organizations", Administration and Society, Vol. 46 No. 5, pp. 496-518. 
Kingma, S. (2018), "New ways of working (NWW): work space and cultural change in virtualizing organizations", Culture and organization, Vol. 1 No. 1, pp. 1-24.

Kok, A., Esten, R. and Helms, R. (2015), "Knowledge sharing in the new world of work: Effects of the New Way of Working", Journal of Information Technology Services, Vol. 14 No. 2, pp. 315-335.

Kolltveit, B., Karlsen, J. and Grønhaug, K. (2005), "Exploiting opportunities in uncertainty during the early project phase", IEEE Engineering Management Review, Vol. 33 No. 1, pp. 26-35.

Kornberger, M. and Clegg, S. (2004), "Bringing space back in: Organizing the generative building", Organization Studies, Vol. 25 No. 7, pp. 1095-1114.

Kyriakidou, V., Michalakelis, C. and Sphicopoulos, T. (2013), "Assessment of information and communication technology maturity level", Telecommunications Policy, Vol. 37 No. 1, pp. 48-62.

Latour, B. and Yaneva, A. (2008), "Give me a gun and I will make all buildings move: An ANT's view of architecture", Explorations in Architecture: Teaching, Design, Research, pp. 80-89.

Leifer, L. and Steinert, M. (2011), “Dancing with ambiguity: Causality behavior, design thinking, and triple-loop-learning", Information Knowledge Systems Management, Vol. 10., pp. 151-173.

Lenfle, S. (2012), "Exploration, project evaluation and design theory: a rereading of the Manhattan case", International Journal of Managing Projects in Business, Vol. 5 No. 3, pp. 486-507.

Lenfle, S., Le Masson, P. and Weil, B. (2016), "When Project Management Meets Design Theory: Revisiting the Manhattan and Polaris Projects to Characterize 'Radical Innovation' and is Managerial implications", Creativity and Innovation Management, Vol. 25 No. 3, pp. 378-395.

Lewis, M., Welsh, A., Dehler, G. and Green, S. (2002), "Product Development Tensions: Exploring Contrasting Styles of Project Management", Academy of Management Journal, Vol. 45 No. 3, pp. 546564.

Lohne, J., Svalestuen, F., Knotten, V., Drevland, F. and Laedre, O. (2017), "Ethical behavior in the design phase of AEC projects, International Journal of Managing Projects in Business, Vol. 10 No. 2, pp. 330-345.

Mahmoud-Jouini, B., Midler, C. and Silberzahn, P. (2016), "Contributions of Design Thinking to Project Management in an Innovation Context", Project Management Journal, Vol. 47 No. 2, pp. 144156.

March, S. and Smith, G. (1995), "Design and natural science research on information technology", Decision Support Systems, Vol. 15, pp. 251-266.

Markus, T. and Cameron, D. (2002), "The Words Between the Spaces: Buildings and Language", Routledge, London and New York.

McKay, J., Marshall, P. and Hirschheim, R. (2012), "The Design Construct in Information Systems Design Science", Journal of Information Technology, Vol. 27 No. 2, pp. 125-139.

Mintzberg, H. (1980), "Structure in 5's: A Synthesis of the Research on Organization Design", Management Science, Vol. 26 No. 3, pp. 322-341.

Orlikowski, W. (1992), "The Duality of Technology: Rethinking the Concept of Technology in Organizations", Organization Science, Vol. 3 No. 3, pp. 398-427. 
Orlikowski, W. and Scott, S. (2008), "Sociomateriality: Challenging the Separation of Technology, Work and Organization", The Academy of Management Annals, Vol. 2 No. 1, pp. 433-474.

Pfeffer, J. and Salancik, G. (1977), "Organization design: The case for a coalitional model of organizations", Organizational Dynamics, Vol. 6 No. 2, pp. 15-29.

Picciotto, R. (2019), "Towards a 'New Project Management' movement? An international development perspective", International Journal of Project Management, in press.

Pinto, J. (2014), "Project management, governance, and the normalization of deviance", International Journal of Project Management, Vol. 32 No. 3, pp. 376-387.

Pipek, V. and Wulf, V. (2009), "Infrastructuring: Toward an Integrated Perspective on the Design and Use of Information Technology", Journal for the Association of Information Systems, Vol. 10, pp. 447-473.

Ribes, D. and Finholt, T. (2009), "The Long Now of Technology Infrastructure: Articulating Tensions in Development", Journal of the Association for Information Systems, Vol. 10, pp. 375-398.

Rylander Eklund, A. and Simpson, B. (2020), "The Duality of Design(ing) Successful Projects", Project Management Journal, Vol. 51 No. 1, pp. 11-23.

Simon, H. (1988), "The Science of Design: Creating the Artificial", Design Issues, Vol. 4 No. 1, pp. $67-82$

Söderholm, A. (2008), "Project management and unexpected events", International Journal of Project Management, Vol. 26 No. 1, pp. 80-86.

Sohi, AJ., Bosch-Rekveldt, M., and Hertogh, M. (2019). Does flexibility in project management in early project phases contribute positively to end-project performance? International Journal of Managing Projects in Business, in press.

Starostka, J. (2015), "Design and design thinking in building an innovative organizational culture", Journal of Intercultural Management, Vol. 6 No.4, pp. 69-79.

Stolterman, E. (2008), "The nature of design practice and implications for interaction design research", International Journal of Design, Vol. 2 No. 1, pp. 55-65.

Taylor, S. and Spicer, A. (2007), "Time for space: A narrative review of research on organizational spaces", International Journal of Management Reviews, Vol. 9 No. 4, pp. 325-246.

Thoring, K., Desmet, P. and Badke-Schaub, P. (2018), "Creative environments for design education and practice: A typology of creative spaces", Design Studies, Vol. 56 No. 1, pp. 54-83.

Våland, M. (2006), "Designing architecture: a potential kinder egg adventure”, Nordic Journal of Architectural Research, Vol. 19 No. 4, pp. 33-44

Våland, M. and Georg, S. (2014), "The socio-materiality of designing organizational change", Journal of Organizational Change Management, Vol. 27 No. 3, pp. 391-406.

Veldhoen, E. (2005), The Art of Working, Academic Service, Den Haag.

Visscher, K., and Visscher-Voerman, J. (2010), "Organizational design approaches in management consulting", Management Decision, Vol. 48 No. 5, pp. 713-731. 
Wastell, D. (2010), "Managing as designing: Opportunity knocks for the IS field", European Journal of Information Systems, Vol. 19 No. 4, pp. 422-431.

Wastell, D. (2014), "Archarios: A dialogue between Socrates and a novice manager on the relevance of design to management practice and education", Academy of Management Learning and Education, Vol. 13 No. 4, pp. 641-652.

Yap, J., Abdul-Rahman, H. and Chen W. (2017), "Collaborative model: Managing design changes with reusable project experiences through project learning and effective communication", International Journal of Project Management, Vol. 35 No. 7, pp. 1253-1271.

Yoo, Y., Boland, R., and Lyytinen, K. (2006), "From organization design to organization designing", Organization Science, Vol. 17 No. 2, pp. 215-229.

Zimmerman, J. and Forlizzi, J. (2008), "The Role of Design Artifacts in Design Theory Construction", Artifact, Vol. 2 No. 1, pp. 41-45. 